\title{
Two Lip Carcinomas following Allogeneic Hematopoietic Stem Cell Transplantation: A Case Report and Literature Review
}

\author{
Nouha Dammak (i), ${ }^{1}$ Latifa Berrezouga, ${ }^{2}$ Manel Njima, ${ }^{3}$ Ines Lahouel, ${ }^{4}$ Mehdi Khemiss (iD), \\ and Mohamed Ben Khelifa ${ }^{2}$ \\ ${ }^{1}$ Medicine and Oral Surgery Department, University Clinic of Dental Medicine, Monastir, Tunisia \\ ${ }^{2}$ Dental Medicine Department, Fattouma Bourguiba Teaching Hospital, Monastir, Tunisia \\ ${ }^{3}$ Anatomical Pathology and Cytology Department, Fattouma Bourguiba Teaching Hospital, Monastir, Tunisia \\ ${ }^{4}$ Dermatology Department, Fattouma Bourguiba Teaching Hospital, Monastir, Tunisia
}

Correspondence should be addressed to Nouha Dammak; dammaknouha11@gmail.com

Received 3 December 2020; Revised 23 June 2021; Accepted 28 July 2021; Published 29 August 2021

Academic Editor: Tommaso Lombardi

Copyright (c) 2021 Nouha Dammak et al. This is an open access article distributed under the Creative Commons Attribution License, which permits unrestricted use, distribution, and reproduction in any medium, provided the original work is properly cited.

\begin{abstract}
Background. Secondary solid cancers are severe complications in patients who have undergone allogeneic hematopoietic stem cell transplantation (AHSCT) for malignant and nonmalignant lymphohematopoietic diseases. Objective. The aim of this work was to report a case of two lip carcinomas following AHSCT and to warn doctors about the importance of regular check-ups of patients who have received HSCT. Observation. A 57-year-old man was referred by the dermatology department for the management of exophytic budding lesions on the lower lip evolving since 5 months. The patient was in complete remission following allogeneic bone marrow transplantation for acute myeloid leukemia since five years. Clinical and histological findings confirmed the diagnosis of a squamous cell carcinoma of the two lesions. Conclusion. It is of paramount importance to seek an oral squamous cell carcinoma in the presence of persistent lesions in HSCT recipients.
\end{abstract}

\section{Introduction}

Following advances in hematopoietic stem cell transplantation (HSCT), an increasing number of patients with hematologic malignancies having cured, leading to a steady increase in the long-term survival among recipients. Unfortunately, survivors are developing late complications following HSCT, for example, secondary solid cancers (SSCs), which are the most serious ones with considerable morbidity and mortality. In fact, in a recent study [1] including nearly 2000 AHSCT recipients, the reported cumulative incidence of SSCs was as follows: $3.2 \%$ at 5 years, $8.7 \%$ at 10 years, and $13.9 \%$ at 15 years after transplantation. Indeed, it has been reported that the risk of developing SSC is 2- to 4-fold higher than that in the general population [2], however, according to Shah et al., the risk of developing oral cancer is 14 times higher [3].
It's worth noting that skin and oral cancers account for approximately one-third of all SSCs in HSCT patients, with oral squamous cell carcinoma being predominant with 50\% of the cases [4-6]. That is why, since the first published case of oral carcinoma after AHSCT by Lishner et al. [7] in 1990, several cases of secondary oral cancer have been reported in the literature. Thus, the present work describes a male patient who developed lower lip squamous cell carcinomas five years after undergoing AHSCT for the treatment of a previous acute myeloid leukemia (AML). A literature review about the development of oral cancer following HSCT was conducted, as well.

\section{Case Report}

A 57-year old man was referred in October 2019 by the dermatology department for the investigation of lesions of the lower lip. No history of tobacco or alcohol consumption 
was recorded. In 2015, the patient underwent AHSCT, following AML with a conditioning regimen including busulfan and cyclophosphamide. A few months later, he developed bronchiolitis obliterans, as an immunological reaction, requiring cyclosporine $\mathrm{A}$ and prednisolone as a treatment for a chronic graft versus host disease (cGvHD). The extra oral examination revealed the presence of two concomitant lesions on the lower lip; the first one was small $(10 \mathrm{~mm})$ with a regular round border and tender on palpation, the second one was rather budding, large (approximately $40 \mathrm{~mm}$ ), crusty, and hemorrhagic (Figure 1). According to the patient, the small lesion appeared three weeks ago, while the largest one has evolved since five months. No cervicofacial lymphadenopathy was detected on palpation. The intraoral examination showed a poor oral hygiene and the absence of other mucosa lesions.

The incisional biopsy of the two lesions, performed under local anesthesia, concluded to well-differentiated squamous cell carcinomas after histological exams (Figure 2). The work-up for extension carried out by ultrasound images and cervico abdomino pelvic computed tomography failed to show associated lymphadenopathy. Indeed, biological exams and full blood counts were within normal limits. The patient was referred to the maxillofacial surgery department, where complete excision of the lesions was undertaken under local anesthesia. Histological exams of the specimen confirmed the diagnosis of well-differentiated squamous cell carcinomas (T2N0M0). The outcome was favorable after a-year follow-up. No evidence of recurrence or metastasis was recorded. The patient was scheduled for a lip reconstructive surgery.

\section{Literature Review}

A review of the literature was conducted using MEDLINE database via its interface PubMed with the following Mesh terms: "cancer, squamous cell," "oral cancer," "carcinoma, squamous cell," "bone marrow cell transplantation," and "hematopoietic stem cell transplantation" and combining the following Boolean equations: $((($ cancer, squamous cell [MeSH Terms]) OR (oral cancer [MeSH Terms]) OR (oral cavity [MeSH Terms]) OR (carcinoma, squamous cell $[\mathrm{MeSH}$ Terms]))) AND ((bone marrow cell transplantation [MeSH Terms]) OR (hematopoietic stem cell transplantation [MeSH Terms])) until August 2020. Selected publications were analyzed according to the following inclusion criteria: HSCT were bone marrow origin, age at OSCC $\geq 14$ years. The exclusion criteria were articles published in a language other than English or French, editor letter, review papers, and conference abstracts. This research concluded to 44 case reports, from 24 articles, about OSCC following HSCT. The information extracted from these cases is summarized in Table 1 and concerned: gender, age at OSCC, tobacco and alcohol use, reason for HSCT, conditioning regimen, interval OSCC-HSCT, GvHD involvement, GvHD treatment or prophylaxis drugs, site and stage of OSCC, and HPV status and outcomes.

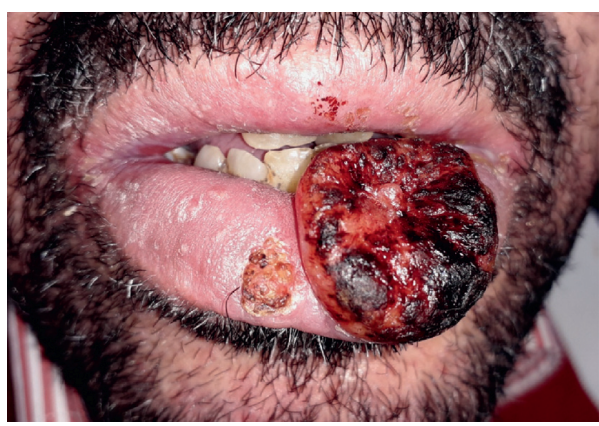

Figure 1: Preoperative view: small lesion with regular round border on the middle lower lip and a large, budding, crusty, and hemorrhagic lesion on the left side of the lower lip.

\section{Discussion}

Malignant and nonmalignant hematological diseases are widely treated by allogeneic hematopoietic stem cell transplantation (HSCT) from peripheral blood, bone marrow, or cord blood. Although HSCT offers curative therapy for these diseases, it exposes recipient survivors to the risk of secondary malignancies development which are classified into three types: posttransplant lymphoproliferative disorders (PTLD), hematologic malignancies, and solid cancers $[5,9]$. The most common secondary malignancies include non-Hodgkin's lymphoma, Hodgkin disease, leukemia in donor-derived cells, and granulocytic sarcoma [27]. Even though, SSCs are less common, a large cohort study [28] conducted by the Center for International Blood and Marrow Transplant Research (CIBMTR) and the Fred Hutchinson Cancer Research Center (FHCRC) reported an increased risk of SSCs. In fact, 189 out of 28.874 included patients developed SSCs after HSCT, with a predominant location in the oral cavity. According to Mawardi et al. [29], oral squamous cell carcinoma (OSCC) is the most common amongst SSCs, with nearly 14 times the risk of developing this cancer compared to the general population. Nevertheless, few case reports and small case series of OSCC following AHSCT have been reported. The present literature review was conducted on oral cancer secondary to HSCT focusing on risk factors related to this condition. Although the conflicting data, several studies have been established to investigate risk factors that might be involved in the development of SSCs in HSCT survivors [2, 28, 30-32].

As for gender, men were considered to be at higher risk for the development of secondary head and neck cancers following HSCT than women $[2,28,30]$. The present review showed 25 males affected and 19 females. Rizzo et al. [28] and Curtis et al. [33] found that males appeared to be slightly higher affected than females, $79 \%$ and $72 \%$, respectively. Moreover, the age at transplantation is more likely to be related to cancer development. The mean age at diagnosis of OSCC was 39.61 years old, and 13 patients were aged more than 50 years. According to Gallagher and Forrest [32] and Shimada et al. [31], a great risk of SSCs seems to be associated to an age over 40 and 45 years, respectively.

However, information regarding tobacco and alcohol consumption is lacking, and knowing that these factors are 


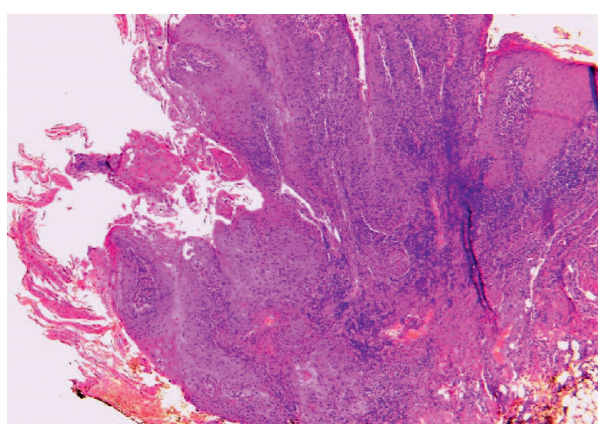

(a)

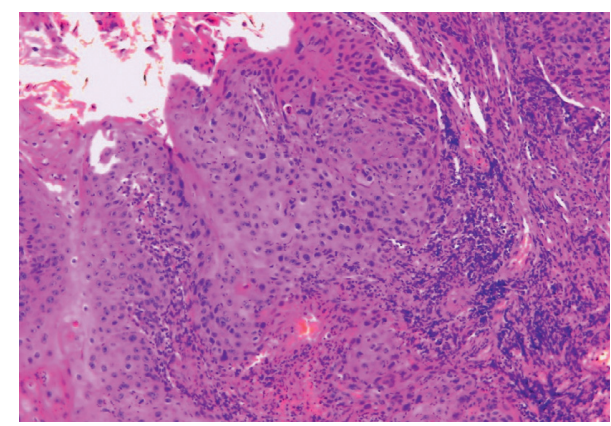

(b)

FIGURE 2: Histological sections: infiltrating carcinomatous proliferation showing squamous differentiation of the labial mucosa (a) small lesion, H\&E: 40; (b) large lesion, H\&E: 100x.

commonly associated with head and neck cancer development, only 6 patients were reported as being addicted to tobacco and alcohol consumption $[3,14,21,26]$. In fact, Curtis et al. [33] failed to prove that tobacco and alcohol are risk factors in the development of OSCC in HSCT survivors.

Results are controversial regarding the relation between the primary disease and the risk of SSCs. Several studies found higher risk for patients diagnosed with Fanconi anemia (FA) and aplastic anemia (AA) [13]. However, Curtis et al. [30] reported that the risk was rather higher in patients with acute and chronic leukemia. Indeed, Martelin et al. [1] concluded that chronic myeloid leukemia (CML) was an independent risk factor for SSCs. The present review showed a predominance of acute myeloid leukemia (AML) (15 cases) against 6 cases of CML $[10,12,16,18,21]$ and 5 cases of FA $[11,23,24,26]$. It's worth to note that myelodysplastic syndrome, PTLD, non-Hodgkin's lymphoma, and acute leukemia predominate early post-HSCT period, while solid cancers occur later $[4,30]$.

In this review, the incidence of SSCs was reported to peak between 8 and 9 years after HSCT, and the risk reaches its peak in children aged 10 years old at the time of transplantation [13]. The median interval for OSCC development was 8.40 years with a longest period of 22 years [9]. Tanaka et al. [2] concluded that the risk of oral cancer development was elevated during the 5-10 years period. Indeed, Rizzo et al. [28] found that risks tended to rise over time for cancers of the oral cavity, and that long-term survivors had significantly elevated (20 to 30 folds) risks of oral cancer during 10 or more years of follow-up.

In the present case, the male patient underwent HSCT for AML at 52 years old. This finding was in agreement with the study of Curtis et al. [30] who concluded that only patients aged 30 years or older at the time of transplantation had a significantly increased risk of solid cancer.

Another considered major risk factor of OSSC development in HSCT recipients is CGvHD with its chronic inflammation. This condition is an alloimmune process secondary to an immune attack by donor $\mathrm{T}$ cells that recognize antigens expressed on normal tissues, including those of the oral cavity [34].

A large cohort study [33] showed that the risk for SCCs increased with the increasing grade of $\mathrm{cGvHD}$, and that patients with severe disease had 10-fold greater risk than those without $c G v H D$. It was also concluded that long-term cGvHD therapy with azathioprine, particularly when combined with cyclosporine and steroids, was a major risk factor of SCC development. In fact the administration for 24 months or more of these drugs can increase sharply the risk of SSCs by nearly 6 to 8 folds. That is the reason why cGvHD, has been described, by some authors, as a precursor state for a potential development of oral cancer in HSCT recipients [3].

The cGvHD has been reported in $25-40 \%$ of HSCT survivors [4,13]. Clinical manifestations most often affect skin, liver, lungs, gastrointestinal tract, and eyes. Aproximately, $80 \%$ of these patients present an oral involvement, comprising lichenoid lesions, atrophy, erythema, xerostomia, and oral pain $[4,13]$. In this review, 40 out of 44 patients developed GvHD. Of whom, 27 developed cGvHD of the oral mucosa prior to OSCC diagnosis $[4-9,11-13,15,16,18,20-23,25]$. The location of GvHD was not precised in 8 patients and not mentioned in 4 patients.

In addition to $\mathrm{CGvHD}$, the use of total body irradiation (TBI) and the intensity of the conditioning regimen are risk factors for secondary malignancies. In this review, conditioning regimens consisted of TBI, chemotherapy, cyclophosphamide combined or not to busulfan, and other drugs [4-6, 8, 12, 14, 16, 19-21]. Curtis et al. [30] reported that the risk of cancer development in recipients who underwent irradiation before HSCT is up to 18.4 times higher than the risk for those who did not undergo irradiation. Indeed, Rizzo et al. [28] found that limited field irradiation (LFI) was associated with an increased risk of SCC of the oral cavity. Majhail et al. [35], however, indicated that the risk of secondary solid malignancies in 4318 HSCT recipients for AML or CML using a high-dose busulphan-cyclophosphamide conditioning regimen are increased even without a prior exposure to LFI or TBI, considering that the absolute risk appeared to be relatively lower. Finally, Shimoni et al. [36] reported that the incidence of secondary malignancies has not decreased in the area of reduced-intensity conditioning and may have even increased when compared with myeloablative conditioning or reduced toxicity conditioning. In the present case, the patient was treated by a combination of 


\begin{tabular}{|c|c|c|c|c|c|c|c|c|c|c|c|c|c|c|c|c|c|}
\hline 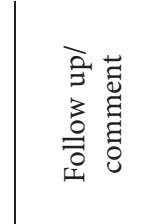 & 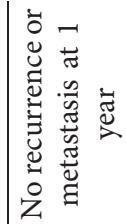 & $\sum$ & 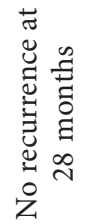 & 㚆 & $\sum_{\bar{z}} \sum_{z}$ & 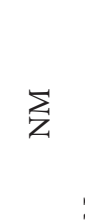 & 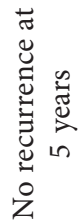 & 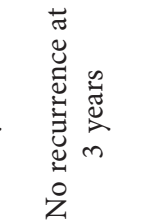 & $\sum$ & & $\sum$ & & ه & 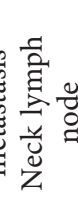 & 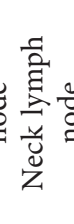 & 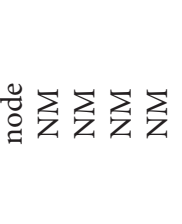 & 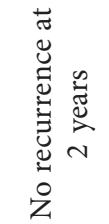 \\
\hline 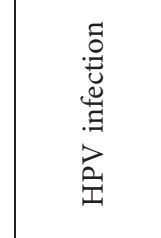 & $\sum_{Z}$ & 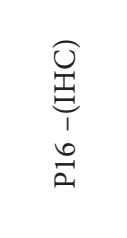 & $\sum_{Z}$ & 玄 & 玄玄 & 文 & $\sum_{\mathrm{Z}}$ & $\sum_{Z}$ & $\sum_{Z}$ & 㚆 & $\sum_{Z}$ & $\begin{array}{l}\hat{n} \\
\hat{n} \\
+ \\
b \\
a\end{array}$ & $\sum_{Z}$ & $\sum_{Z}$ & $\sum_{\bar{Z}}$ & 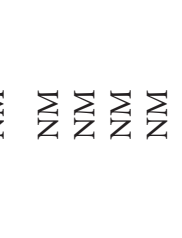 & $\begin{array}{l}1 \\
b \\
a \\
1 \\
b \\
a\end{array}$ \\
\hline 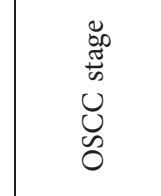 & $\sum_{\substack{0 \\
ٍ}}^{0}$ & $\underset{\mathrm{H}}{\mathbb{V}}$ & $\sum_{Z}$ & $\begin{array}{l}\vec{z} \\
\stackrel{a}{\bar{z}} \\
\vec{F}\end{array}$ & $\sum_{\text {音 }}^{\text {号 }}$ & $\sum_{Z}$ & $\sum_{Z}$ & $\sum$ & 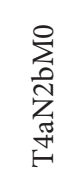 & ${ }_{2}^{0}$ & 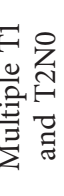 & 㠵 & $\sum_{Z}$ & $\sum_{Z}$ & $\sum$ & $\sum_{Z} \sum_{Z} \sum_{Z}$ & 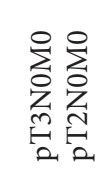 \\
\hline $\begin{array}{l}\stackrel{0}{5} \\
0 \\
0 \\
0 \\
0\end{array}$ & 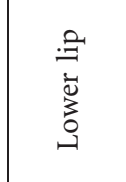 & 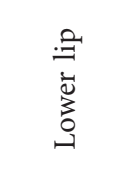 & 㩊 & 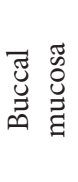 & 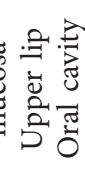 & 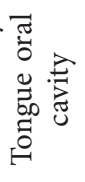 & . & 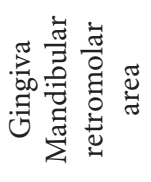 & 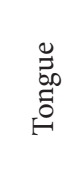 & 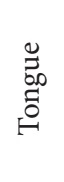 & 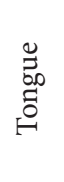 & 㺃 & 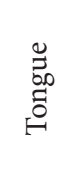 & 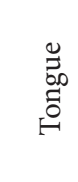 & $\begin{array}{l}\mathscr{0}_{0} \\
\stackrel{0}{0} \\
\stackrel{0}{0}\end{array}$ & 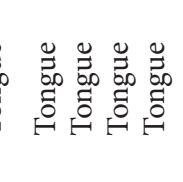 & 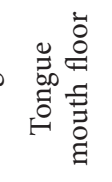 \\
\hline 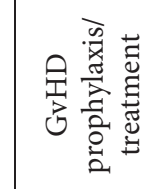 & $\frac{\overrightarrow{1}}{3}$ & 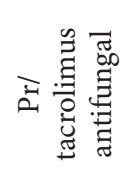 & $\sum_{j}^{\infty}$ & $\sum_{Z}^{\Sigma}$ & $\sum_{z} \sum_{z}$ & $\sum$ & 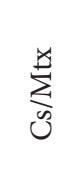 & 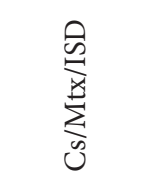 & 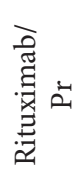 & 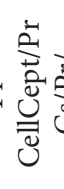 & 这苟 & $\frac{1}{3}$ & 㓂 & $\hat{\triangleq}$ & $\triangleq$ & 合忩忩 & 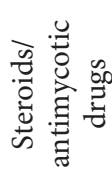 \\
\hline 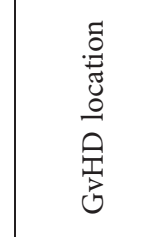 & $\begin{array}{l}\mathscr{6} \\
\Xi \\
\Xi\end{array}$ & $\begin{array}{l}\sum \\
0 \\
y \\
\text { 泀 }\end{array}$ & $\sum$ & $\begin{array}{l}\sum \\
0 \\
\hat{\frac{1}{\omega}}\end{array}$ & 正 & $\triangleq$ & $\sum_{0}$ & 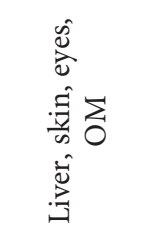 & $\sum_{Z}$ & $\sum$ & $\sum_{Z}$ & $\begin{array}{l}\hat{0} \\
\vdots \\
\vdots \\
\hat{0} \\
0 \\
\hat{0} \\
\hat{0}\end{array}$ & $\sum$ & $\sum_{0}$ & $\sum_{0}$ & $\sum_{0} \sum_{0} \sum_{0} \sum_{0}$ & ప్̃ \\
\hline 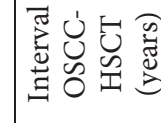 & in & $m$ & ก & $\circ$ & $\sigma \stackrel{\sharp}{b}$ & 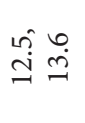 & 우 & $m$ & $\Xi$ & $\therefore$ & $\sim$ & N & $\vec{n}$ & $\stackrel{n}{m}$ & $\ddot{a}$ & $\stackrel{\infty}{=} \underset{i}{\sim} \stackrel{\sim}{0} \stackrel{-}{\infty}$ & $\approx$ \\
\hline 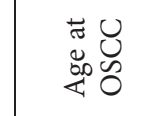 & in & $\stackrel{\infty}{\sim}$ & $\vec{n}$ & $\infty$ & $\stackrel{\infty}{\sim} \stackrel{\infty}{m}$ & $\begin{array}{l}\text { f } \\
\text { if }\end{array}$ & $\stackrel{\infty}{-}$ & $\stackrel{\infty}{\sim}$ & $\hat{\sigma}$ & के & in & $\stackrel{n}{m}$ & nิ & $\vec{n}$ & $\stackrel{0}{\sim}$ & 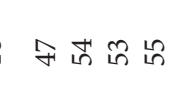 & i \\
\hline 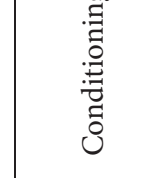 & 量 & $\sum_{Z}$ & 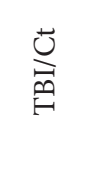 & $\vec{Q}$ & 玄充 & $\sum_{Z}$ & 3 & 3 & $\sum_{Z}$ & $\sum_{Z}$ & $\sum_{Z}$ & 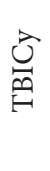 & $\sum_{Z}$ & $\begin{array}{l}\text { 花 } \\
0 \\
\text { z }\end{array}$ & $\vec{p}$ & 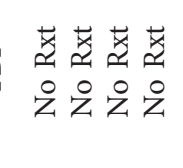 & 之 \\
\hline 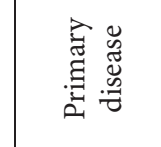 & $\sum_{4}^{\mid}$ & 马 & $\sum_{\&}^{B}$ & $\mapsto$ & $\sum_{i}$ & $\underset{j}{\mid \vec{z}}$ & 左 & 左 & $\sum_{\bar{Z}}$ & 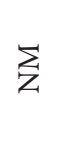 & $\sum_{Z}$ & 安 & $\sum_{4}$ & $\sum_{<}^{\mid \vec{z}}$ & $\sum_{4}^{\xi}$ & 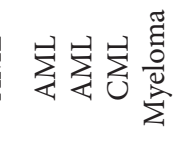 & 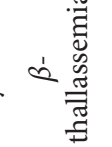 \\
\hline 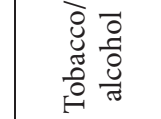 & z & $\sum_{Z}$ & z̊ & ż & 串玄 & $\sum_{Z}$ & ż & z̊ & z̊ & 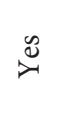 & z̊ & $\sum_{Z}$ & $\stackrel{\circ}{z}$ & $\ddot{z}$ & ż & z̊z̊z̊z̊ & z̊ \\
\hline $\begin{array}{l}\overrightarrow{\tilde{v}} \\
\overrightarrow{0} \\
0\end{array}$ & $\Sigma$ & $\Sigma$ & $\Sigma$ & $\Sigma$ & $\Sigma \Sigma$ & $\omega$ & $\omega$ & 山 & $\omega$ & 山 & $\Sigma$ & $\Sigma$ & $\Sigma$ & $\Sigma$ & $山$ & $\Sigma \omega \Sigma \omega$ & 山 \\
\hline 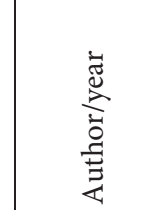 & 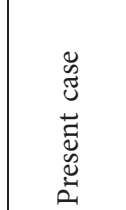 & 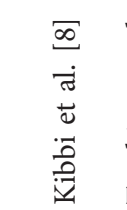 & 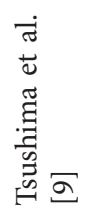 & 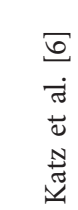 & : & 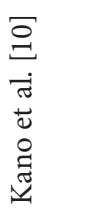 & \multicolumn{2}{|r|}{ 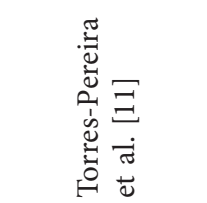 } & & 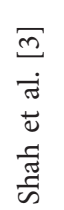 & & 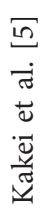 & & 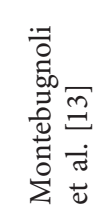 \\
\hline
\end{tabular}




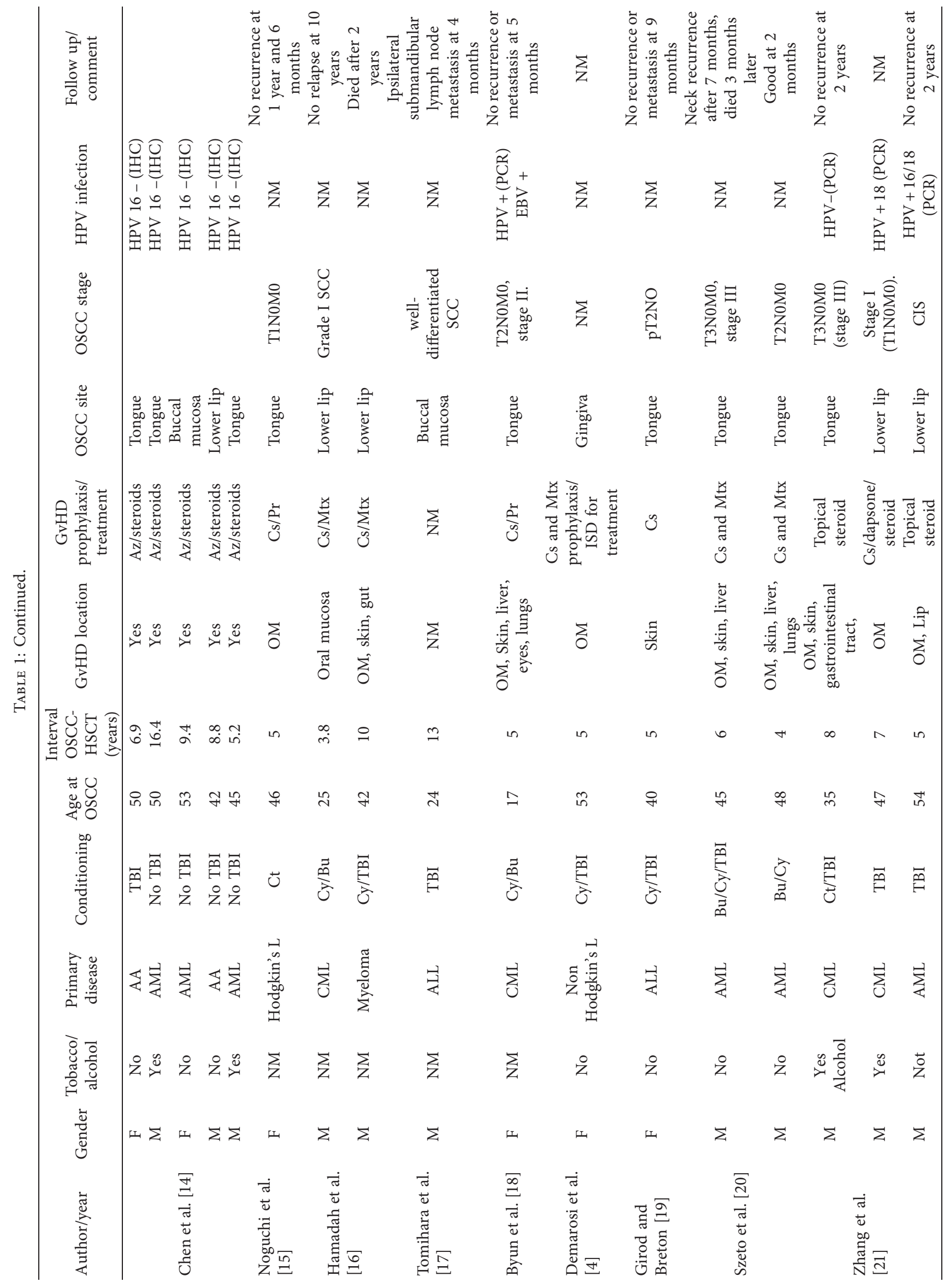




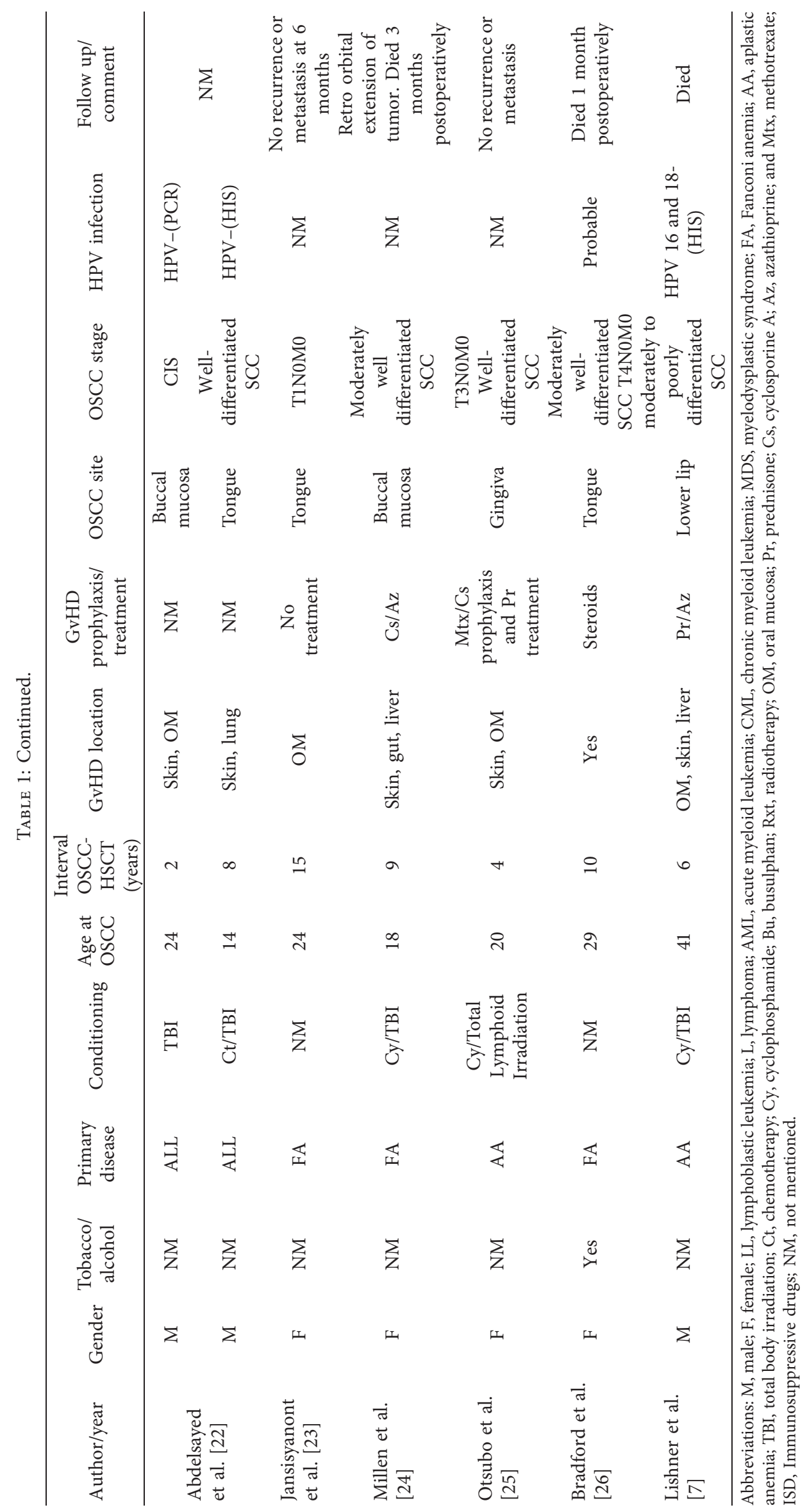


busulfan and cyclophosphamide, no irradiation regimen was administered, but information regarding GvHD oral manifestations are lacking.

As for oral location, most of OSCCs were located on the tongue (25 cases/56.81\%), then the lip ( 8 cases/18.18\%) and the gingiva (5 cases/11.36\%). The buccal mucosa and the floor of the mouth were less affected. For lip locations, 7 cases concerned the lower lip [7, 8, 14, 16, 21], and only one case occurred on the upper lip [6]. It is worth noting that, apart from older age, male gender, and fair skin, sun and UV exposure are amongst risk factors involved in actinic or solar cheilosis, which is a premalignant ulcerative lesion most frequently associated with SCC of the lip that represents up to $25-30 \%$ of all oral cancers [37]. In the review, almost all patients experienced GvHD, despite the prophylaxis treatment, in some cases. None of the authors reported a history of sun or UV exposure, but a chronic inflammation related to the immune reaction secondary to GvHD. In fact, it has been reported that tissue damage by diffuse $\mathrm{T}$-cell infiltration in the subepithelial buccal mucosa and in the minor salivary glands may be at the origin of lichen-like changes, ulceration, and erythema. These lesions may predispose to malignant transformation along with immunosuppressive therapy $[13,34]$. Consequently, as the patient is working at an industrial paint shop and is not an outdoor laborer (for example, farmer) with prolonged sun exposure to the face, we assume that the oral location of the $\mathrm{cGvHD}$ is the lower lip, as reported by some authors $[6,21]$.

Indeed, to the best of our knowledge, this is the first condition where two synchronous cancers appeared on the same anatomical site. The time interval between the two lesions was nearly 4 months; this is in agreement with that recorded by Montebugnoli et al. [13] who described SCC of the tongue and floor of the mouth four months apart. Nonetheless, it is more likely that the small lesion is an extension of the larger one, because, the epithelium might be infiltrated by tumoral cells as the distance between the 2 lesions is very small (less than $2 \mathrm{~mm}$ ) and histological features of the 2 specimen were identical, as well.

Finally, some authors evaluated the Human Papilloma Virus (HPV) infection in OSCC after HSCT, as it was proposed that head and neck cancers may be correlated with this oncogenic virus infection. In this review, the isolation of HPV high risk genotypes 16 and 18 was conducted in 16 cases. Of these, 4 were positive and 2 of them were located on the lower lip [21]. Some authors postulated that the reactivation of HPV in these immunocompromised recipients may contribute to cancer development $[12,21,26]$.

\section{Conclusion}

Dentists and surgeons should be aware of the following;

(i) Secondary malignancy development is a potential long-term complication in patients receiving HSCT

(ii) HSCT recipients experiencing $\mathrm{cGvHD}$ are at higher risk of developing OSCC

(iii) Careful oral examination and regular evaluation for premalignant lesions and biopsy of any suspicious lesions are required for HSCT recipients, even for a long time after transplantation.

Further studies including a large cohort are needed to better understand the relation between GvHGD and the development of SSCs in HSCT recipients.

\section{Data Availability}

All the data are available from the corresponding authors upon request.

\section{Conflicts of Interest}

The authors declare no conflicts of interest.

\section{References}

[1] E. Martelin, L. Volin, M. Itälä-Remes et al., "Incidence and risk factors of secondary cancers after allogeneic stem cell transplantation: analysis of a single centre cohort with a long follow-up," Bone Marrow Transplantation, vol. 54, no. 2, pp. 334-337, 2019.

[2] Y. Tanaka, S. Kurosawa, K. Tajima et al., "Increased incidence of oral and gastrointestinal secondary cancer after allogeneic hematopoietic stem cell transplantation," Bone Marrow Transplantation, vol. 52, no. 5, pp. 789-791, 2017.

[3] A. T. Shah, E. Wu, and R. O. Wein, "Oral squamous cell carcinoma in post-transplant patients," American Journal of Otolaryngology, vol. 34, no. 2, pp. 176-179, 2013.

[4] F. Demarosi, D. Soligo, G. Lodi, L. Moneghini, A. Sardella, and A. Carrassi, "Squamous cell carcinoma of the oral cavity associated with graft versus host disease: report of a case and review of the literature," Oral Surgery, Oral Medicine, Oral Pathology, Oral Radiology, and Endodontology, vol. 100, no. 1, pp. 63-69, 2005.

[5] Y. Kakei, M. Akashi, H. Komatsubara, T. Minamikawa, and T. Komori, "p16 overexpression in malignant and premalignant lesions of the oral and esophageal mucosa following allogeneic hematopoietic stem cell transplantation," Head and Neck Oncology, vol. 4, no. 38, pp. 1-4, 2012.

[6] J. Katz, M. Nadim Islam, I. Bhattacharyya, P. Sandow, and J. S. Moreb, "Oral squamous cell carcinoma positive for $\mathrm{p} 16 /$ human papilloma virus in post allogeneic stem cell transplantation: 2 cases and review of the literature," Oral Surgery, Oral Medicine, Oral Pathology and Oral Radiology, vol. 118, no. 3, pp. e74-e78, 2014.

[7] M. Lishner, B. Patterson, R. Kandel et al., "Cutaneous and mucosal neoplasms in bone marrow transplant recipients," Cancer, vol. 65, no. 3, pp. 473-476, 1990.

[8] N. Kibbi, K. C. Suozzi, C. J. Ko, and D. J. Leffell, "Squamous cell carcinoma of the lip in a patient with graft-versus-host disease," Dermatologic Surgery, vol. 45, no. 7, pp. 1002-1005, 2019.

[9] F. Tsushima, J. Sakurai, and H. Harada, "A case of upper gingiva carcinoma with chronic graft-versus-host disease after allogenic bone marrow transplantation," Australian Dental Journal, vol. 60, no. 3, pp. 404-407, 2015.

[10] Y. Kano, H. Ishii, M. Konno et al., "Cells of origin of squamous epithelium, dysplasia and cancer in the head and neck region after bone marrow transplantation," International Journal of Oncology, vol. 44, no. 2, pp. 443-450, 2014.

[11] C. C. Torres-Pereira, R. T. Stramandinoli-Zanicotti, J. M. Amenábar et al., "Oral squamous cell carcinoma in two 
siblings with Fanconi anemia after allogeneic bone marrow transplantation," Special Care in Dentistry, vol. 34, no. 4, pp. 212-215, 2014.

[12] J. C.-K. Chung, R. K.-Y. Tsang, V. S.-H. To et al., "Secondary head and neck cancer in patients with history of hematological malignancy," Head \& Neck, vol. 35, no. 5, pp. 729-732, 2013.

[13] L. Montebugnoli, D. B. Gissi, C. Marchetti, and M. P. Foschini, "Multiple squamous cell carcinomas of the oral cavity in a young patient with graft-versus-host disease following allogenic bone marrow transplantation," International Journal of Oral and Maxillofacial Surgery, vol. 40, no. 5, pp. 556-558, 2011.

[14] M. H. Chen, P. M. Chang, W. Y. Li et al., "High incidence of oral squamous cell carcinoma independent of HPV infection after allogeneic hematopoietic SCT in Taiwan," Bone Marrow Transplantation, vol. 46, no. 4, pp. 567-572, 2011.

[15] K. Noguchi, M. Nakase, M. Inui, S. Nakamura, K. Okumura, and T. Tagawa, "A case of tongue carcinoma associated with chronic graft-versus-host disease after allogeneic haematopoietic stem cell transplantation," Australian Dental Journal, vol. 55, no. 2, pp. 200-202, 2010.

[16] I. Hamadah, Y. Binamer, S. Alajlan, A. Nassar, and A. J. M. Saleh, "Squamous cell carcinoma of the lip after allogeneic hemopoietic stem cell transplantation," Hematology/Oncology and Stem Cell Therapy, vol. 3, no. 2, pp. 84-88, 2010.

[17] K. Tomihara, H. Dehari, A. Yamaguchi et al., "Squamous cell carcinoma of the buccal mucosa in a young adult with history of allogeneic bone marrow transplantation for childhood acute leukemia," Head \& Neck, vol. 31, no. 4, pp. 565-568, 2009.

[18] J.-H. Byun, B.-W. Park, J.-R. Kim, G.-W. Lee, and J.-H. Lee, "Squamous cell carcinoma of the tongue after bone marrow transplant and graft-versus-host disease: a case report and review of the literature," Journal of Oral and Maxillofacial Surgery, vol. 66, no. 1, pp. 144-147, 2008.

[19] A. Girod and P. Breton, "Deux cas de tumeurs malignes de la face après allogreffe de cellules souches hématopoïétiques," Revue de Stomatologie et de Chirurgie Maxillo-faciale, vol. 106, no. 2, pp. 107-110, 2005.

[20] C. H. Szeto, T. W. H. Shek, A. K. W. Lie, W. Y. Au, A. P. W. Yuen, and Y. L. Kwong, "Squamous cell carcinoma of the tongue complicating chronic oral mucosal graft-versushost disease after allogeneic hematopoietic stem cell transplantation," American Journal of Hematology, vol. 77, no. 2, pp. 200-202, 2004.

[21] L. Zhang, J. B. Epstein, C. F. Poh et al., "Comparison of HPV infection, p53 mutation and allelic losses in post-transplant and non-posttransplant oral squamous cell carcinomas," Journal of Oral Pathology \& Medicine, vol. 31, no. 3, pp. 134-141, 2002.

[22] R. A. Abdelsayed, T. Sumner, C. M. Allen, A. Treadway, G. M. Ness, and S. L. Penza, "Oral precancerous and malignant lesions associated with graft-versus-host disease: report of 2 cases," Oral Surgery, Oral Medicine, Oral Pathology, Oral Radiology, and Endodontology, vol. 93, no. 1, pp. 75-80, 2002.

[23] P. Jansisyanont, A. Pazoki, and R. A. Ord, "Squamous cell carcinoma of the tongue after bone marrow transplantation in a patient with Fanconi's anemia," Journal of Oral and Maxillofacial Surgery, vol. 58, no. 12, pp. 1454-1457, 2000.

[24] F. J. Millen, M. G. Rainey, J. M. Hows, P. A. Burton, G. H. Irvine, and D. Swirsky, "Oral squamous cell carcinoma after allogeneic bone marrow transplantation for Fanconi anaemia," British Journal of Haematology, vol. 99, no. 2, pp. 410-414, 1997.

[25] H. Otsubo, H. Yokoe, T. Miya et al., "Gingival squamous cell carcinoma in a patient with chronic graft-versus-host disease," Oral Surgery, Oral Medicine, Oral Pathology, Oral Radiology, and Endodontology, vol. 84, no. 2, pp. 171-174, 1997.

[26] C. R. Bradford, H. T. Hoffman, G. T. Wolf, T. E. Carey, S. R. Baker, and K. D. McClatchey, "Squamous carcinoma of the head and neck in organ transplant recipients: possible role of oncogenic viruses," The Laryngoscope, vol. 100, no. 2 Pt 1, pp. 190-194, 1990.

[27] H. J. Kolb, G. Socié, T. Duell et al., "Malignant neoplasms in long-term survivors of bone marrow transplantation," Annals of Internal Medicine, vol. 131, no. 10, pp. 738-744, 1999.

[28] J. D. Rizzo, R. E. Curtis, G. Socié et al., "Solid cancers after allogeneic hematopoietic cell transplantation," Blood, vol. 113, no. 5, pp. 1175-1183, 2009.

[29] H. Mawardi, S. Elad, M. E. Correa et al., "Oral epithelial dysplasia and squamous cell carcinoma following allogeneic hematopoietic stem cell transplantation: clinical presentation and treatment outcomes," Bone Marrow Transplantation, vol. 46, no. 6, pp. 884-891, 2011.

[30] R. E. Curtis, P. A. Rowlings, H. J. Deeg et al., "Solid cancers after bone marrow transplantation," New England Journal of Medicine, vol. 336, no. 13, pp. 897-904, 1997.

[31] K. Shimada, T. Yokozawa, Y. Atsuta et al., "Solid tumors after hematopoietic stem cell transplantation in Japan: incidence, risk factors and prognosis," Bone Marrow Transplantation, vol. 36, no. 2, pp. 115-121, 2005.

[32] G. Gallagher and D. L. Forrest, "Second solid cancers after allogeneic hematopoietic stem cell transplantation," Cancer, vol. 109, no. 1, pp. 84-92, 2007.

[33] R. E. Curtis, C Metayer, J. D Rizzo et al., "Impact of chronic GVHD therapy on the development of squamous-cell cancers after hematopoietic stem-cell transplantation: an international case-control study," Blood, vol. 105, no. 10, pp. 3802-3811, 2005.

[34] J. M. Fall-Dickson, S. Z. Pavletic, J. W. Mays, and M. M. Schubert, "Oral complications of chronic graft-versushost disease," Journal of natural cancer institute monographs, vol. 53, 2019.

[35] N. S. Majhail, R. Brazauskas, J. D. Rizzo et al., “Secondary solid cancers after allogeneic hematopoietic cell transplantation using busulfan-cyclophosphamide conditioning," Blood, vol. 117 , no. 1 , pp. $316-322,2011$.

[36] A. Shimoni, N. Shem-Tov, A. Chetrit et al., "Secondary malignancies after allogeneic stem-cell transplantation in the era of reduced-intensity conditioning; the incidence is not reduced," Leukemia, vol. 27, no. 4, pp. 829-835, 2013.

[37] A. Y. Han, E. C. Kuan, J. M. St Clair, J. E. Alonso, A. Arshi, and M. A. St John, "Epidemiology of squamous cell carcinoma of the lip in the United States: a population-based cohort analysis," JAMA Otolaryngology Head and Neck Surgery, vol. 142, 2016. 